\title{
Radix Entomolaris: A Case Report.
}

\author{
Dr.Mahendra Patel ${ }^{1}$, Dr. Anjali Oak ${ }^{2}$, Dr.Aditi Soni ${ }^{3}$ \\ 1,2,3 (Department of conservative dentistry and endodontics, CDSRC, Gujarat University, India)
}

\begin{abstract}
Successful root canal treatment depends on proper biomechanical preparation of all the canals in the concerned tooth so as to receive 3-D filling with an inert obturating material. Problems in clinical practice are encountered when anatomically different teeth are supposed to undergo root canal therapy. Mandibular molar normally has two roots (mesial and distal) and three canals (mesio-lingual, mesio-buccal and distal). When an extra root is present lingually, it is termed radix-entomolaris. It is of prime importance to clean and shape the canal present in this extra root for a successful root canal treatment of the same. Failure to do so won't give desired results which hence emphasizes the need to have knowledge regarding such anatomical variants.
\end{abstract}

Keywords: Anatomical variations, Mandibular molar, Radix entomolaris

\section{Introduction}

Success of an endodontic procedure depends on thorough cleaning and shaping of root canal followed by three dimensional obturation of pulp canal space providing an appropriate hermetic seal.A clinician should have complete knowledge about possible anatomical variation while treating teeth endodontically. Chances of improper bio-mechanical preparation followed by inadequate irrigation increases when clinician fails to recognize aberrations in canal morphology. ${ }^{1,2}$

Mandibular molars usually have two roots and three canals. But it is not uncommon to find extra distal canal and extra root in these teeth. Presence of additional root lingually is termed radix entomolaris, where as presence of similar extra root bucally is termed radix paramolaris. ${ }^{2,3,4}$ Carabelli was the first one to describe radix entomolaris in mandibular first molar. Mandibular first molar shows higher percentof such supernumerary root, which are rare to find in mandibular second and third molars. ${ }^{2,3}$

Incidence of radix entomolaris differs greatly with the ethnicity of population and is shown to be very low in Indian population, which is around $0.2 \%{ }^{3}$ This case report shows management of such a rare entity in an Indian patient.

\section{Case Report}

A 45 year old patient reported to the department of conservative dentistry and endodontics, with the chief complain of pain in lower right back tooth region since 15 days. Patient's medical history was noncontributory. Heat test showed lingering painful response even after removal of stimulus, suggestive of irreversible pulpitis. Also tooth was tender on percussion. Radiographically, deep carious lesion approaching pulp with widening of periodontal space could be seen suggestive of chronic irreversible pulpitis with apical periodontitis.

Tooth was isolated with the help of rubber dam and local anesthesia (Inferior alveolar nerve block) administered. Access opening was made followed by establishment of apical patency with \#10 K hand-file. Bio-mechanical preparation was completed using Protaper Hand filesupto F2 (DentsplyMaillefer, Switzerland). Working length was obtained with \#15k file. On changing the angulation of $x$-ray tube, presence of third root was observed. $2.5 \%$ Sodium hypochlorite and Normal saline were used as irrigants. Calcium Hydroxide intracanal medicament was given and patient was recalled after 7 days. Intra-canal medicament was changed twice in similar manner andmaster cone X-ray was taken and the obturation was carried out (Fig1 and 2), once the patient was asymptomatic, with Protaper F2 gutta-percha cones and zinc oxide eugenol sealer. Post endodontic restoration was done and patient was recalled for follow up after 1 week. Patient was absolutely asymptomatic then. 


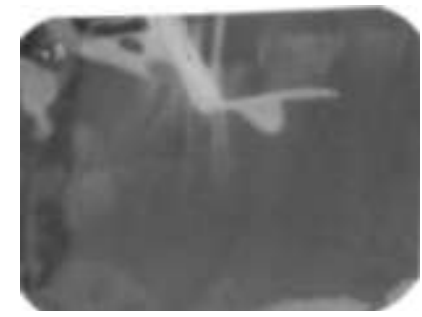

[Figure 1: Master cone x-ray]

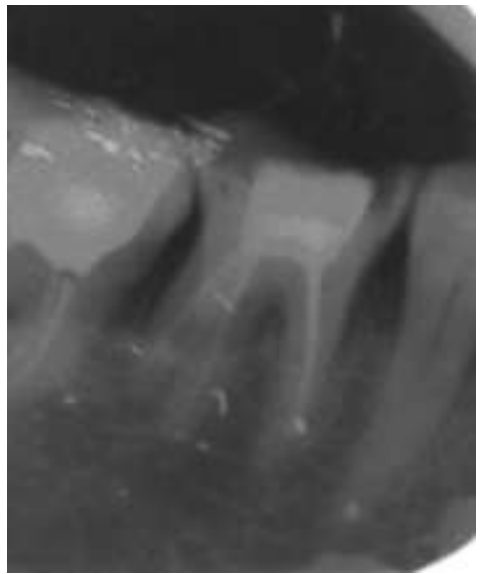

[Figure 2:Obturation X-ray]

\section{Discussion}

The etiological factors leading to formation of radix entomolaris are still not clear. Dysmorphic supernumerary root may be due to external factors during odontogenesis or presence of atavastic genes. In eumorphic roots, racial genetic factors seems influential. ${ }^{5}$ Presence of radix entomolaris may vary from a short conical root to the one that has full length. Sometimes hidden roots can be seen as a shadow near the distal root. ${ }^{6}$ This emphasizes the careful reading of pre-operative radiographs. Also radiographs at differenthorizontal angulations (mesially or distally) should be attempted in case of doubt regarding morphology of teeth.

Many times endodontic treatment tend to fail if such extra anatomical variations are not recognised by the operator. The extra canals harbouring micro-organisms are left untreated and can lead to flare-ups. There is increased possibility of detecting and managing radix entomolarisby obtaining straight line access, modifying the shape of access opening to trapezoid, magnification with help of loupes or dental operating microscope.

\section{References}

[1] Prabhu NT, Munshi AK. Additional distal root in permanent mandibular first molars: report of a case. Quintessence International 1995; 26(8): 567-9.

[2] Segura-Egea JJ, Jimenez-Pinzon A, Rios-Santos JV. Endodontic therapy in a 3-rooted mandibular fi rst molar: Importance of a thorough radiographic examination. J Can Dent Assoc 2002; 68(9): 541-4.

[3] Tu MG, Huang HL, HsueSS et al . Detection of permanent three-rooted mandibular first molar by cone-beam computed tomography imaging in Taiwanese individuals. J Endod 2009; 35: 503-7.

[4] Wasti F, Shearer AC, Wilson NHF. Root canal systems of the mandibular and maxillary first permanent molar teeth of south Asian Pakistanis.IntEndod J. 2001; 34:263-6.

[5] De Moore RJ, Deroose CA, Calberson FL. The radix entomolaris in mandibular first molar: an endodontiic challenge. IntEndod J. 2004; 37:789-99.

[6] Sperber GH, Moreau JL. Study of the number of roots and canals in Senegalese first permanent mandibular molars.IntEndod J. $1998 ; 31: 117-22$. 